\title{
The Analysis of Anti-language from the Perspective of Current Situation of Netspeak
}

\author{
Shi Baihui, Li Fengjie \\ Foreign Languages Department, School of Humanities, Tianjin University of Finance and Economics, Tianjin, China
}

Email address:

yyfx0901@163.com (Li Fengjie)

To cite this article:

Shi Baihui, Li Fengjie. The Analysis of Anti-language from the Perspective of Current Situation of Netspeak. International Journal of Language and Linguistics. Vol. 5, No. 2, 2017, pp. 50-56. doi: 10.11648/j.ij11.20170502.14

Received: March 1, 2017; Accepted: March 14, 2017; Published: April 14, 2017

\begin{abstract}
One of the design features of language is creativity which can differentiate human beings from animals. Anti-language is a special form of language which generates from traditional society and language but different from them in some ways. Anti-language plays a role in creating and maintaining social structure through conversation as traditional language does but the social structure it maintains shares some special modalities and is very different from the traditional ones. As a special form of anti-language, Netspeak is very familiar these years and is developing rapidly with its special advantages. What's more, some netspeak has been used in official websites such as China Daily. It is necessary for us to have a study on netspeak to figure out the basic information of the usage of netspeak in China as well as have in-depth knowledge of the fundamental state which can contribute to the research on anti-language in return.
\end{abstract}

Keywords: Anti-language, Traditional Language, Netspeak, Age

\section{Introduction}

As a social symbol system, language can reflect the social attitude and create social identities. Anti-language, as a special form of language, verifies closely the relationship between language and society. The concept "anti-language" was firstly put forward and studied by linguist $\mathrm{M} \cdot \mathrm{A} \cdot \mathrm{K} \cdot$ Halliday in the journal American Anthropologist in 1976.

At certain times and places we come across special forms of language generated by some kind of anti-society; these we may call "anti-languages" (Halliday, 1976:570).

Anti-society was set up within another society and was against the dominant one, thus the users of anti-language are usually the ones who stand at the edge of the dominant society and are hostile to the dominant social activities. "An anti-society is a society which is a conscious alternative to the existing one. It is a mode of resistance that may take the form either of passive symbiosis or of active hostility and even destruction." For example, the "pelting (=paltry) speech" which is said by a large number of vagabonds, or "cursitors" as their own tongue who lived off the wealth of the established society, and the grypserka (used by Polish prison and reform schools), criminal cant, Qumran Hebrew, the pagan language and Calcutta underworld language, etc.

An important question is that why anti-language is used by people. Mallik answered the question in Language of the Underworld of West Bengal in 1972. Mallik found that of all 400 criminals and anti-social elements, 385 replies have been gotten, and 158 of them attribute to the need for secrecy and 132 as communicative force or verbal art. The need for secrecy is often explained as to divide the "members" and the "outsides" in the anti-society. We can understand this point easily. Identity is important evidence that can tell others who you really are. Only if identity is verified, things can move on as predicted.

An anti-language is the means of realization of a subjective reality: not merely expressing it, but actively creating and maintaining it (Halliday, 1976:576). It is another language. The language is secret because the reality is secret. Accordingly the techniques of information control practiced by individuals have something to hide, which they don't want divulged. The speakers of an anti-society are constantly striving to maintain a counter-reality which is under pressure from the established world. That is why the language is constantly renewing itself -- to sustain the vitality that it needed if it is to function at all. Words and modes of expressions come out rapidly. The expressions 
seem to be oblique, diffuse, metaphorical from the point of established language but appear directed, as powerful manifestations of the linguistic system in the service of the construction of reality if seen in their own terms.

The researches on anti-language or any aspect of anti-language are quite limited both in China and abroad until now and most of the research achievements derived from and are rooted in $\mathrm{M} \cdot \mathrm{A} \cdot \mathrm{K} \cdot$ Halliday's Anti-languages published in the journal American Anthropologist in 1976. We can say that Anti-languages by Halliday is the handbook of subsequent related study on it.

CNKI (China National Knowledge Infrastructure) is one of the most authoritative academic websites in China and one of the most valuable Chinese websites who owns maximized information around the world. The content in it include periodicals and magazines, newspapers, theses, dissertations, conference papers, books and patents of different disciplines and of great collection value and use value which is usually regarded as criteria of academic research as well as scientific policy-makings. We input "anti-language" in CNKI by searching the title only (in order to make the results more precise and accurate) and get 8 results only and input "făn yǔyán" (the Chinese name of "anti-language") 26 results. Those articles were published from 2008 to 2016 . The study on anti-language is rare. These articles include Anti-language as Social Semiotic: The Social Interpretation of Marginalized Discourse by Ding Jianxin published in Foreign Language Research in 2010 (Ding Jianxin, 2010:76-83); Anti-languages, Lexico-grammar and the Internet Language by $\mathrm{Li}$ Zhanzi and Pang Chaowei published in Foreign Languages in China in 2010 (Li Zhanzi, 2010); The Social Function Research of Anti-language by Xia Huiyan et al. published in Journal Of Tianjin Foreign Studies University in 2013 (Xia Huiyan, 2013); A Survey of Critical Discourse Analysis and Anti-language Studies by Jia Yali and Xia Huiyan (Jia Yali and Xia Huiyan, 2012); Anti-language and Anti-language Group by $\mathrm{Wu}$ Haibin $(\mathrm{Wu}$ Haibin, 2013); A Probe of the Construction of identity from the Anti-language feature of Netspeak by He Xiangjun (He Xiangjun, 2015); An Analysis on Anti-language and the Construction of Alternative World from the Perspective of Phtosophy of Language-Take Nadsat in A Clockwork Orange for Example by Huang Yanjuan (Huang Yanjuan, 2013) etc.

As a newborn anti-language phenomenon, netspeak and the study on it seem to be necessary and essential. This paper tries to study the anti-language from the aspect of current situation of netspeak and makes contribution to the study of anti-language further.

\section{Types of Anti-language}

Social dialects are not necessarily associated with caste or class; they may be religious, generational, sexual, economic (urban or rural), and perhaps other things too. What distinguishes them is their hierarchical character (Halliday, 1976:580). Anti-language is, at one and the same time, both the limiting case of a social dialect and a language.

\subsection{Underworld Language}

A typical kind of anti-language is underworld language which is usually used among prisons or gangdom. The anti-languages of prison and criminal countercultures are the most clearly defined because they have specific reference to alternative social structures, as well as the additional attributes of secret languages and professional jargons (Halliday, 1976:583). For instance: "Policemen" are often called "dirt" or "tiáo zl" in Chinese by prisoners. What's more, they use "fish" for new criminals, "bath salt" for drug, "cleaner" for the hit man, "bird" or "duck" for new message or letter sent from the jail, "get off the train/ to be on the bush/ to go over the wall/ to crush out" for prison break, etc.

\subsection{Lavender Language}

An example of anti-language that is associated with sex is lavender language. It functions as a kind of homosexual code, characterized by acronyms, plays on words and double meanings only intended to be understood by the gay community which can help them communicate and differentiate the heterosexuals. The lavender language includes words or expressions like gay (faggotry), lesbian (tribade), bisexual, couple, straight (heterosexual), bent (homosexual), out of the closet (to admit the identity of homosexual to the public), Macho Queen, O-Le (old lesbian), butch, femme, Queer, Dyke, Gay Pride etc.

\subsection{Netspeak}

Halliday treats language as a kind of social semiotic. "Semiotic" is not a static concept which means that the meaning of language is not fixed and it is generated and understood in the process of concrete usages. We treat language as a social semiotic which means that it is a part of as well as the product of social culture and a semiotic system which expresses the meaning under a given cultural background (Halliday, 2001:25). The creativity of language makes it resourceful and innovative.

Netspeak is a typical example of linguistic revolution since the Internet has enriched the structures and functions of language. Internet has become a totally new community for the netizens in which people can speak what they think is cool and popular. Therefore, new words or expressions appear. Sometimes netspeak is only used for convenience or vividness and sometimes in order to be vogue and distinctive. As a special kind of language, netspeak is used on the internet to chat, search information, play games, send e-mails or post blogs by more and more people. As time goes by and because of the development of cyber world, netspeak develops rapidly and the forms are becoming more and more diversiform. For instance,

$\mathrm{BTW}=$ by the way

ASAP $=$ as soon as possible

Netizen $=$ net + citizen 


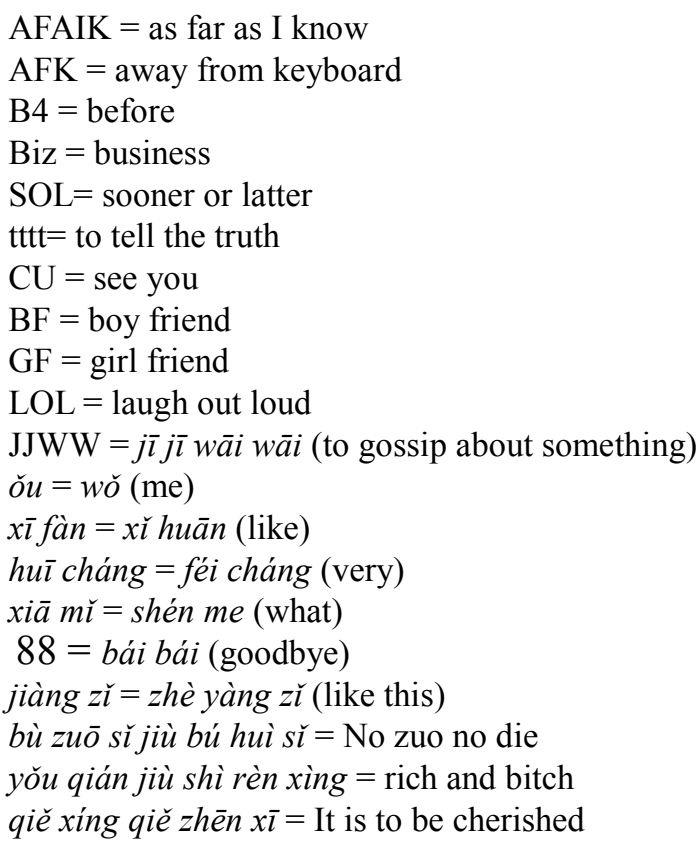

\section{Characteristics and Forms of Anti-language}

\subsection{Relexicalization}

One of the most obvious characteristics of anti-language is that new words are used to replace old ones, which is a language relexicalized. In relexicalization, new words are often invented or old words are used by representing new meanings. It is a process of creation or innovation. New things appear and maintain. According to the design features of language, Saussure refers to the fact that the forms of linguistic signs bear no natural relationship to their meanings which is called arbitrariness. Arbitrariness of language makes it potentially creative. We can find it in Shakespeare's sonnet "a rose by any other name would smell as sweet". In anti-society, words or expressions may change, but the meaning remains the same.

\subsection{Overlexicalization}

It is obvious, however, the language is not merely relexicalized in the above-mentioned areas: it is overlexicalized. Such as in Mallik's account of the Calcutta underworld language we find not just one word for "bomb" but 21; 41 words for "police," and so on (Mallik, 1972:22-23). There are dozens of expressions of cannabis in English such as "marijuana, hemp, marihuana, bhang, cunjah, weed, hashish, gigglesmoke, Marry Warner" etc. Some of them are formal expressions and some come from cant or argot. All of these reflect the characteristic of overlexicalization in anti-language.

\subsection{Homophone}

In addition, the patterns of anti-language may appear at all levels such as phonological, lexicogrammatical and semantic such as homophone. A homophone is a word that is pronounced the same as another word but differs in meaning, and may differ in spelling too. The words may be spelled the same, such as "rose" (flower) and "rose" (past tense of the verb "rise"), or differently, such as "carat", "caret", and "carrot", or "to", "two", and "too". Many netizens use numbers which pronounce the same instead of words or change Chinese characters into the ones that sounds similar for the sake of convenience and saving time. For example:

$2 \mathrm{~B}$ or not $2 \mathrm{~B}=$ to be or not to be (the pronunciation of letter " $\mathrm{B}$ " is the same as the word "be");

B4 = before ("B" pronounces the same as syllable "be" in "before");

1314 =in one's whole life (" 3 "sounds similar to Chinese character "shêng" and the same is true for "4" as "shi");

$520=$ I love you (" 5 " sounds similar to Chinese character "wǒ", so do "2" and " 1 " which refers to " $a \imath$ " and " $n \iota$ ");

$3 \mathrm{Q}=$ Thank you (in Chinese, " 3 " sounds alike to " $\theta$ " in "[$[\theta æ \eta \mathrm{k}]$ "and the same to "Q" when there's a liaison between "Thank" and "you")

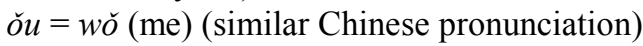

hū cháng = feì cháng (very much) (similar Chinese pronunciation)

$x \bar{l}$ fàn $=x \grave{\imath}$ huān (like) (similar Chinese pronunciation)

\subsection{Abbreviation}

Another type of way of formation of anti-language is abbreviation. Many words have come into being through abbreviation. An abbreviation is a shortened form of a word or phrase. It consists of a group of letters taken from the word or phrase. This phenomenon is also called clipping. A new word is created by cutting the final part (from "advertisement" to "ad"), cutting the initial part (from "telephone" to "phone") or cutting both the initial and final parts accordingly (from "refrigerator" to "fridge"). For instance,

asap $=$ as soon as possible (made up from the first letters of each word)

$\mathrm{tttt}=$ to tell the truth (the same as above)

btw $=$ by the way (the same as above)

$\mathrm{DIY}=$ do it yourself (the same as above)

$\mathrm{SOHO}=$ small office home office (the same as above)

$\mathrm{JJWW}=j \bar{\imath} j \bar{\imath} w a \bar{\imath} w a \bar{l}$ (the first letters of Chinese pinyin)

Sol $=$ sooner or latter (made up from the first letters of each word)

$\mathrm{CU}=$ see you (the same as above)

$\mathrm{BF}=$ boy friend (the same as above)

$\mathrm{GF}=$ girl friend (the same as above)

$\mathrm{LOL}=$ laugh Out loud (the same as above)

\subsection{Creation}

As time goes by and because of the development of cyber world, netspeak develops rapidly and the forms are becoming more and more diversiform. The creativity of language makes netspeak resourceful and creative. There is an increasing number of new wordings appearing from day to day. For instance, 
bù zuō sǐ jiù bú huì š̌ = No zuo no die

yǒu qián jiù shì rèn xìng $=$ Rich and bitch

qiě xíng qiě zhēn $x \overline{1}=$ It is to be cherished.

Yě shì zuì le = I'm speechless.

băo zhèng bù dă sǐ nǐ = I give my word to spare your life.

wǒ dú shū shaǒ nǐ bié piàn wǒ $=$ Don't take advantage of my illiteracy.

nà huà miàn tài meǐ wǒ bù găn kàn $=\mathrm{I}$ can't afford to take $\mathrm{a}$

look at it.

rán ér bìng méi yǒu shén me luăn yòng $=$ But it is of no damn use.

chéng huì wán = Your urban folks are really born to mock!

čr kè wǒ de neì xīn jī hū shì bēng kuì de $=$ My heart is

almost collapsed at the moment.

nà me wèn tí lái le $=$ Here's the question.

\section{The Current Situation of Netspeak}

Netspeak has developed rapidly these years. Many new expressions are familiar to people such as "kōng cháo (empty nest)", “ wō jū (Dwelling Narrowness)", "maō nú (cat slave: the people who raise cats and spoil them very much)", "luó hün (naked marriage)" "miaō xīng rén (the cat)". What's more, some netspeak has been approved by the government. For example, "no zuo no die (means if you don't do stupid things, they won't come back and bite you in the ass, 'zuo' is a Chinese character meaning 'acting silly or daring')" is a Chinese joke used to be facetious and this phrase has been taken down in Urban Dictionary (an American online slang dictionary) as more and more people know it and use it. Furthermore some netspeak has been used in official websites such as China Daily. Netspeak like "miaō xīng rén", "shàng tiān" and "māo nú" have been used in China Daily in a report "The first five-star hotel for cats in the world comes into being where hairdressing and dating are available". If you search "empty nest" in Baidu News, you can get approximately 107,000 pieces of news online and "luó hün" 24,400 results etc.

In order to figure out the basic information of the usage of netspeak in China and have in-depth knowledge of the fundamental state, we do a survey by the way of questionnaire on the current situation of netspeak in China. 160 people have participated in this survey and the people come from 22 provinces and 4 municipalities in China from teenagers to the elderly which is a large span. According to their basic information such as sex, age, education background, everyday language, preferred language, their attitude towards netspeak, the reasons of usage and influence of netspeak etc, we can have a more accurate and authentic condition on netspeak which can help us understand more and deeply.

\subsection{Analysis for Individual Elements}

Among all of the 160 respondents, 73 are male and 87 are female. We divide the people into four groups by age: below 20 years old, 20 to 35 years old, 36 to 50 and above 50 . There are 18 persons below 20 and 120 from 20 to 35 years old, 17 from
36 to 50 and only 5 who is more than 50 . The percentages accordingly are $11.25 \%, 75 \%, 10.63 \%$ and $3.13 \%$. We can see that most of the users of netspeak age between 20 to 35 who is very young and as the popularization of the Internet, teenagers are becoming more and more popular and keep pace with fashion trend as the adults.

\subsubsection{Education Background}

At the same time, the people with a college degree are $65.63 \%$ of all and $14.38 \%$ of respondents with a postgraduate degree or above. The people who have a high school certificate is $11.25 \%$ and only $8.75 \%$ of people's highest degree is middle school or below. We can infer from this that $80.01 \%$ of the respondents have the college degree or above and the usage of netspeak mostly happen to be the people who have high education background. As a new and special form of anti-language, netspeak seems to be vogue and attractive and the people who are highly educated are more willing to accept the new things compared with others, which is related to their education and mode of thinking received in university. College students are more willing to and take delight in new and exotic things. They are more open-minded, receptive and easier to try out new ideas. Hence, netspeak has found a fertile field to grow up and propagate in colleges.

\subsubsection{Daily Language}

As for daily language, more than $65 \%$ of people use mandarin in their everyday life and $26.25 \%$ use mandarin and dialects at ordinary times and only $8.75 \%$ use dialects daily. What's obvious to us is that, none use network as their daily language in this survey. We can't say that there is nobody using netspeak daily around us; however, what we can say is that the people who regard netspeak as their everyday language is pretty rare. Even though the netspeak becomes more and more popular and familiar day by day especially among the young and the new generation, few people use them daily and it is called "netspeak" because of its relation to "net" inevitably, meaning that netspeak is and still is a modality using online, using it in normal times may seems "peculiar" or "not acceptable" so far from the eye of ordinary people.

\subsubsection{Basic Attitudes}

When it refers to the attitudes towards netspeak, the ratio of the people who like and like very much is $35.01 \%$ altogether and most of the persons don't like or dislike netspeak with the number of 98 people. Only $3.13 \%$ dislike and only 1 person dislike it very much.

76 persons prefer traditional language while 29 favor netspeak, and the number of the people who regard traditional language and netspeak the same are 33. Meanwhile 22 are indifferent to this problem. When it refers to the question that the number of people using netspeak around you. 43 reply that the number is quite large and 92 (the largest ratio) think it's okay and only $15.63 \%$ say that the number is small or very small. We learn that quite a large number of people are using netspeak in their life more or less and netspeak has diffused on a large scale and developed quickly. Now that there are many people using netspeak, can people accept the ones who use 
netspeak around them? The answer is that $65 \%$ are able to accept and $14.38 \%$ feels hard to accept and $20.68 \%$ don't care about that. It shows that netspeak has been accepted by the majority of people at present which means it can spread and develop constantly. Nevertheless, it doesn't mean that it progresses perfectly. There are many deficiencies instead and one of the biggest problems is that people consider it not standard enough. $57.5 \%$ of them regard it not precise and $8.75 \%$ ill-formed. Only $33.75 \%$ think it okay.

\subsubsection{Advantages of Netspeak}

Since many of us can accept netspeak appearing by our side and there are quite a lot using it more or less, so it is important to know the reasons why they use netspeak sometimes instead of traditional language. This is a multiple choice. It shows in this survey that the biggest reason that netspeak is used is the diversity in forms and interesting modality which accounts for $65 \%$. The second cause is to follow the trend and be fashionable which occupies $47.5 \%$. There are also a number of people using netspeak because of its convenience and efficiency in their daily life and the ratio is $41.88 \%$. Of all the respondents, $62.5 \%$ regard netspeak vivid and lively which contributes to their communication and $22.5 \%$ think it doesn't have obvious weaknesses in their conversation. It's worth noting that there still are $12.5 \%$ saying netspeak is elusive and crabbed which is unfavorable for them to exchange information during the communication. Meanwhile a tiny number of people consider it vulgar and uncourteous.

\subsection{Cross-Over Analysis}

The results above are analyzed by only one factor or single question. By cross-over analysis, we can get more accurate answers, find out the elements that affect the results and their interrelationships as well.

If we regard age as independent variable and the attitude towards netspeak as dependent variable, then we get results like this.

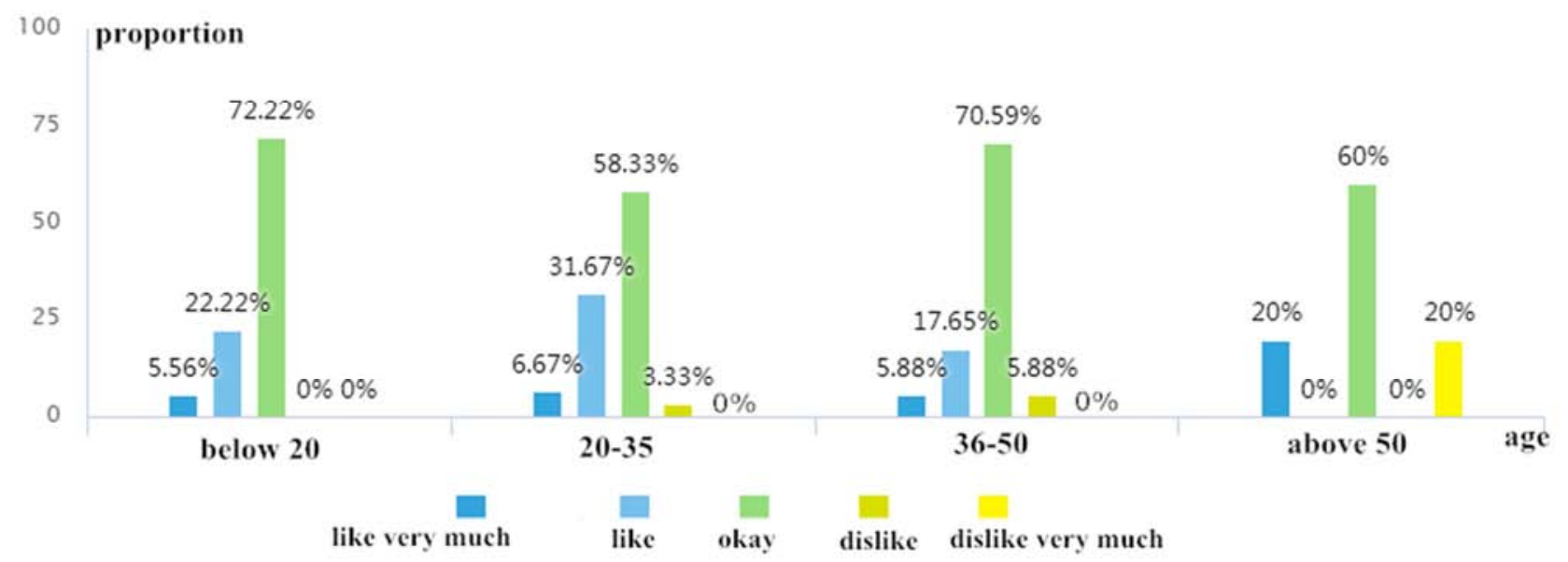

Figure 1. The relationship between age and people's attitudes towards netspeak.

From the figure, we can learn that no matter what age the respondent is, their most possible attitudes to netspeak are "okay" and the proportion of degree of dislike emotion increases as age increases too. The older they are, the less capable of accepting netspeak in their life. One of the reasons is that netspeak is a totally new thing appearing in recent years for them and being adapted to traditional language and traditional life style make them fairly hard to take in newborn things like this. While at the same time, netspeak seems to be very popular among the young with very few people who dislike it. The majority of people still accept and welcome it to be a new part of their life.

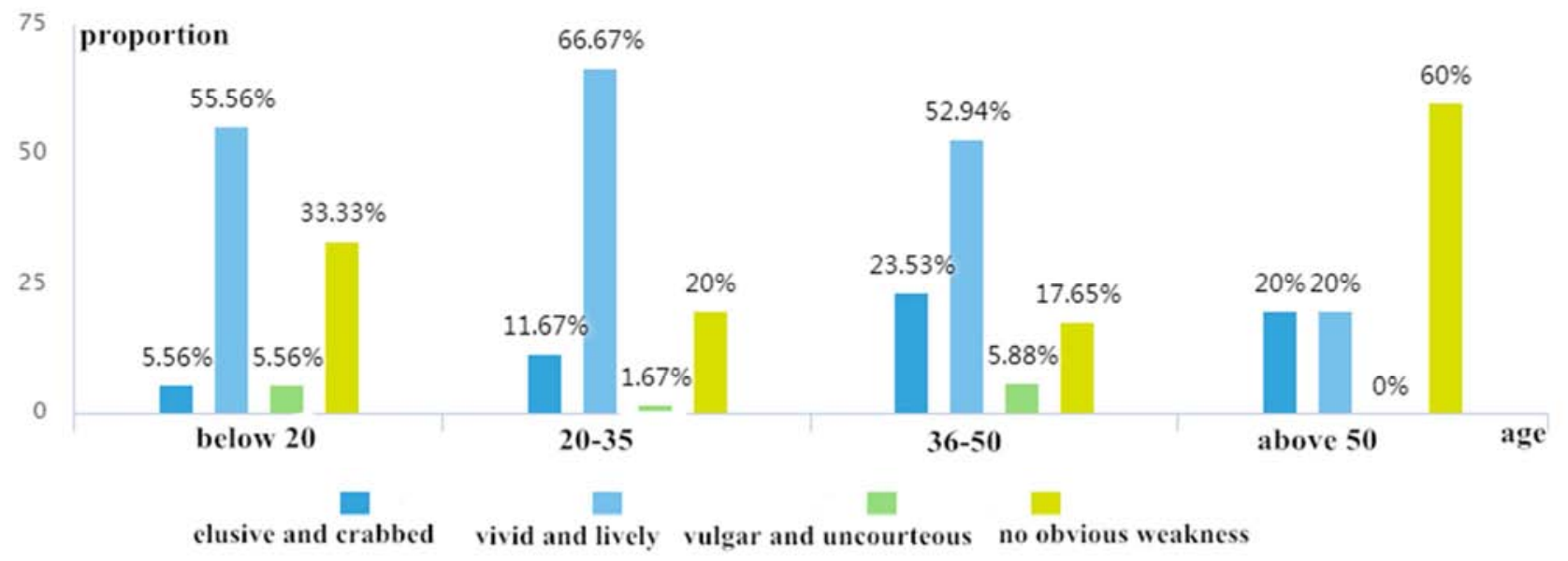

Figure 2. The relationship between age and what people think of the netspeak in usage. 
This is the figure of the relationship between age and what people think of the netspeak in usage. $20 \%$ of people over 50 years old feel netspeak elusive and crabbed for them to understand. It is a high rate compared with other groups'. It can be another reason why many people over 50 can't accept netspeak like the young. We can say that besides their traditional ideology, the obstacles they face are much more compared with the young. More than half of the people from below 20 to 50 years old consider netspeak is very vivid and lively which contributes to expression and communication.

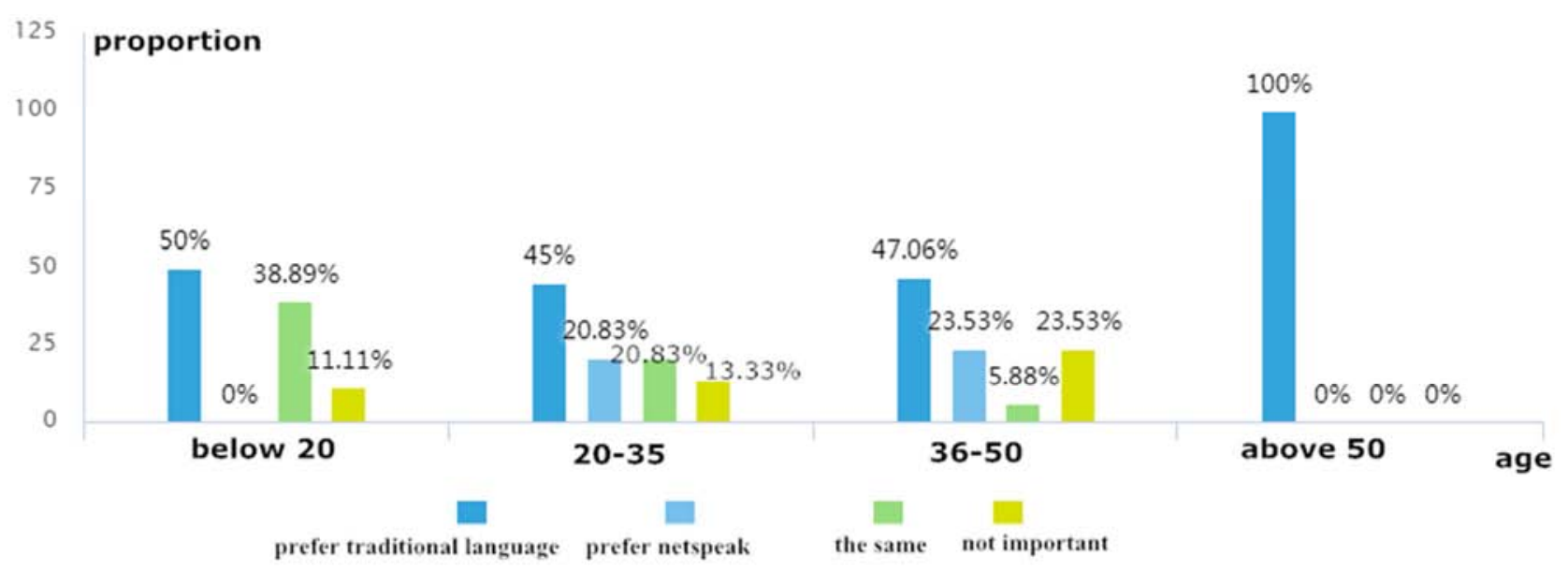

Figure 3. The relationship between age and preferred daily language.

By combining age and preferred daily language, we get Figure 3. The ratios of "prefer traditional language" of four groups: below 20, 20-35, 36-50 and above 50 are all the highest ones compared with "prefer netspeak", "the same" or "not important". Though netspeak develops fast these years especially among the young, traditional language still has overwhelming superiority at present. Netspeak enriches human's lives but will not be equal to or replace traditional language at least for the present.

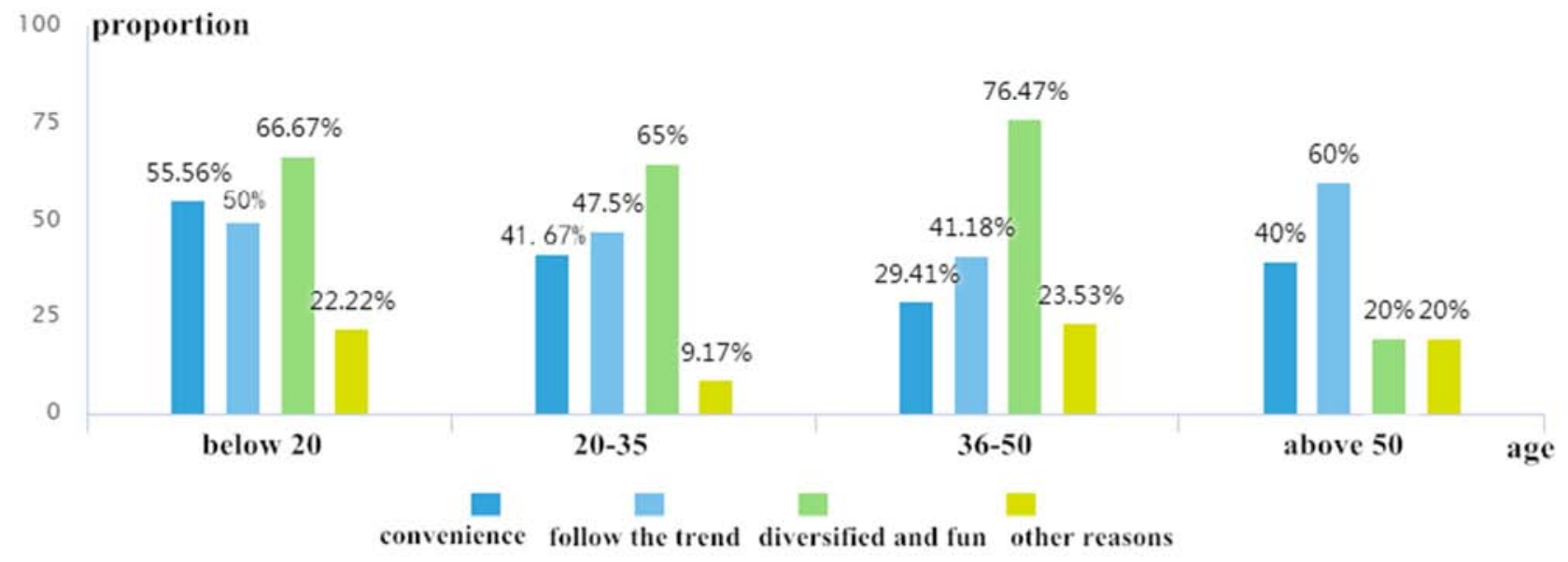

Figure 4. The relationship between age and reasons of using netspeak.

The option "diversified and fun" is the highest percentage from below 20 to 50 years old while "follow the trend" is the highest option for the people over 50. It reflects that most of the young and adults below 50 are usually attracted by the diversity in forms and interesting modality. Because of the different patterns of manifestation, netspeak can catch people's eyeballs instantly which is very glaring compared with prim traditional language. However, the people over 50 are most likely to be drawn to the option "follow the trend". There's no doubt that netspeak enjoys great popularity among the young and it seems that it is one of the marks of vivifying "young man". No one likes to be old at least in others' eyes. Hence in order to be young and dynamic, some of them use netspeak to follow the trend. What's more, the children of the people over 50 are usually in their 20 s or 30 s which means they are the main users of netspeak. Knowing and using netspeak will help to eliminate the generation gap and facilitate the relationships between parents and their children.

\section{Conclusion}

As a special form of language deviated from traditional ones, netspeak has positive significance to some extent. It can 
enrich the forms of language and help to facilitate linguistic diversity. Meanwhile netspeak has been accepted by the majority of people at present which means it can spread and develop constantly. Nevertheless, it doesn't mean that it progresses perfectly. Netspeak is and still is a modality using online, using it in normal times may seem "peculiar" or "not acceptable" so far for most ordinary people. All in all, the study of netspeak can help us know more about fundamental information of today's society in many fields such as education, politics, culture, economics and historical research etc.

\section{References}

[1] Mallik, Bhaktiprasad, 1972, 'Language of the Underworld of West Bengal'. Research Series. Calcutta: Sanskrit College. No. 76.

[2] Halliday, M. A. K. 1976, 'Anti-languages'. American Anthropologist. Vol. 78, No. 3, pp. 570-584.

[3] Halliday, M. A. K. 2001, 'Language as Social Semiotic: The Social Interpretation of Language and Meaning'. Foreign Language Teaching and Research Press.
[4] Ding Jianxin. 2010, 'Anti-language as Social Semiotic: The Social Interpretation of Marginalized Discourse'. Foreign Language Research. No. 2, pp. 76-83.

[5] Li Zhanzi \& Pang Chaowei. 2010, 'Anti-languages, Lexico-grammar and the Internet Language'. Foreign Languages in China. Vol. 7, No. 3.

[6] Xia Huiyan. et al. 2013, 'The Social Function Research of Anti-language'. Journal of Tianjin Foreign Studies University. Vol. 20, No. 4.

[7] Jia Yali \& Xia Huiyan. 2012, 'A Survey of Critical Discourse Analysis and Anti-language Studies'. Journal of Anhui University of Technology (Social Sciences). Vol. 29, No. 4.

[8] Wu Haibin. 2013, 'Anti-language and Anti-language Group'. Journal of South China University of Technology (Social Science Edition). Vol. 15, No. 3.

[9] He Xiangjun. 2015, 'A Probe of the Construction of identity from the Anti-language feature of Netspeak'. English on Campus. Vol. 16. 229-230.

[10] Huang Yanjuan. 2013, 'An Analysis on Anti-language and the Construction of Alternative World from the Perspective of Phtosophy of Language - Take Nadsat in A Clockwork Orange for Example'. Journal of Minjiang University. Vol. 34, No. 3 . 